between consumers and organizations appropriating something with little awareness and no choice of what they have just gifted to a website.

However, as noted earlier, there are already checks and balances DP, PECS as they stand, increasing general awareness about privacy and settings - people being enlightened and empowered at their own pace, organizations increasingly realizing the value of clear privacy policies. Non-intrusive cookies may be quite low down the list of privacy breakers, and we do need the regulator to take a measured approach to the mechanics used to gain consent. Privacy is part of a landscape, not something that stands in isolation from everything else, and it should not be artificially drawn out in a way that results in confusion and annoyance, and no real value.

The ICO is the regulator, not the enactor or legislator; they are trying to assist, and they do plan to publish more guidance. We shouldn't shoot the messenger, but compliance resources need to be used and applied sensibly. So let's hope the ICO is pragmatic beyond May 2012, and focuses its pursuit of compliance (and certainly any strong sanctions) on those whose businesses are based on more intrusive cookies, digital tracking and messaging, who are not being clear and straightforward with users. Also that the ICO continues to work with Government, industry and other stakeholders in the development of recognizable mechanisms for making choices that those consumers can have confidence in managing.

Note

1. The ICO would like to use cookies to store information on your computer, to improve our website. One of the cookies we use is essential for parts of the site to operate and has already been set. You may delete and block all cookies from this site, but parts of the site will not work. To find out more about the cookies we use and how to delete them, see our privacy notice.

$\square$ I accept cookies from this site.

\title{
Did mass-mailing to 6,000 nurses breach database right?
}

\section{Stephen Groom}

Journal of Direct, Data and Digital Marketing Practice (2012) 13, 256-257. doi:10.1057/dddmp.2011.39

Topic: Direct marketing

Who: Beechwood House Publishing Ltd v Guardian Products Ltd \& Anor Where: Patents County Court, England

Law stated as at: 5 September 2011 
Osborne Clarke is one of Europe's most respected law firms. This year it has yet again been rated in the top tier for advertising, marketing and brand management by the UK's leading legal directories and its website www. marketinglaw.co.uk, launched in 1999 and updated monthly ever since, continues to be a unique online resource for UK and international advertising and marketing law. Any enquiries regarding this section should be sent to stephen.groom@ osborneclarke.com

\section{What happened}

- Medical supply specialist Guardian (GP) obtains from Precision Direct Marketing (PDM) 8,363 records of practice nurses in UK (the 'List')

- PDM got the List from Bespoke Database Organisation (BDO).

- BDO got the List from Binley's by way of a single usage licence.

- The List contained 'seed' names planted by Binleys.

- The seeds received the GP mailing.

- Binley's sued for database right infringement.

- Was the Binley's list protected by database right under the Copyright and Rights in Databases Regulations 1997 (SI 1997/3032)?

- If so, had GP and PDM infringed that right?

\section{The Verdict}

- The work involved in compiling the database including sending 13,000 questionnaires fulfilled the 'substantial investment' requirement.

- 6,000 nurse records in the List, which came from the 43,000 records in Binley's list were a substantial part of Binley's list.

- Database right infringed by

- PDM and GP loading the List onto their computers and

- GP printing nurse names and addresses in the List onto letters for the GP mailing

\section{Why this matters}

Since the 'sui generis' database right was introduced in the United Kingdom in 1997 by way of the Copyright and Rights in Databases Regulations 1997, cases in which databases have been held by UK judges to jump the high hurdle set by the Directive and qualify for the EU-created 'database right' have been few and far between.

With the vast majority of databases also deprived of copyright protection, this has not looked good for the marketing industry, but this case shines a ray of hope and confirms that protection will be available if evidence can be produced that sufficient investment in terms of expense and effort has gone into creating the database in question.

The judgment does not deal with the level of damages awarded, which may be left to a further hearing. We will monitor developments and report any news on this if and when it materializes.

Stephen Groom, Head of Marketing and Privacy Law, Osborne Clarke, London

E-mail: stephen.groom@osborneclarke.com 